\title{
Serum anti-Mullerian hormone and homocysteine in premenopausal females with and without cardiovascular disease
}

\author{
Huma Khan ${ }^{1 *}$, Madhur M. Gupta ${ }^{2}$ \\ ${ }^{1}$ Undergraduate, ${ }^{2}$ Department of Biochemistry, NKP SIMS and RC, Nagpur, Maharashtra, India \\ Received: 17 December 2018 \\ Accepted: 11 January 2019 \\ *Correspondence: \\ Dr. Madhur M. Gupta, \\ E-mail: drmadhur20@rediffmail.com \\ Copyright: $\odot$ the author(s), publisher and licensee Medip Academy. This is an open-access article distributed under \\ the terms of the Creative Commons Attribution Non-Commercial License, which permits unrestricted non-commercial \\ use, distribution, and reproduction in any medium, provided the original work is properly cited.
}

\begin{abstract}
Background: The objective of this study is to assess the association of anti-Mullerian hormone (AMH) and homocysteine (Hcy) levels in premenopausal females with and without cardiovascular disease.

Methods: A case control study was conducted in premenopausal, menopausal and normal fertile females $(\mathrm{n}=30)$ with and without cardiovascular disease in a tertiary care hospital and research centre in central India. Fasting sample obtained was assessed for AMH and Hcy levels. Results were compared and data was analyzed.

Results: The levels of AMH and Hcy were significantly altered in premenopausal and menopausal females as compared to normal fertile females. Moreover, there was a weak correlation when intergroup comparison was made between the parameters in females with and without cardiovascular disease.

Conclusions: A prospective study with a larger sample size to assess levels of AMH need to be performed to provide insight in premenopausal females for the early detection cardiovascular disease.
\end{abstract}

Keywords: Anti-Mullerian hormone, Cardiovascular disease, Homocysteine, Pre-menopause

\section{INTRODUCTION}

Premenopause is the first stage of the menopause process. It is the time in a woman's life in which she is fully fertile. Premenopausal women are relatively protected from coronary artery disease and atherosclerosis as compared to postmenopausal women, and this protection is attributed to the effects of the female sex hormone (estrogen). Still mortality from ischaemic heart disease remains higher in women than in men. ${ }^{1}$ The atheroprotective effects of estrogen, a female hormone is basically recognized to its effects on serum lipid concentrations and cholesterol levels. ${ }^{2}$ However, recently reports suggest that estrogen therapy has no effect on the progression of coronary atherosclerosis in women with established disease. Anti-Mullerian hormone (AMH) produced by granulose cells of small follicles in the ovary has recently emerged as an important marker of ovarian reserve and reproductive performance. ${ }^{3}$ It is a homodimeric glycoprotein belonging to the transforming growth factor- $\beta$ (TGF- $\beta$ ) super family. ${ }^{4}$ AMH has been reported to fall to very low levels as early as 5 years prior to the final menstrual period and ovarian production of $\mathrm{AMH}$ ceases as women enter menopause. This is a continuum rather than an abrupt event. It is said that AMH positivity correlates with primordial follicle member ovarian reserve in women. Atsma et al, in 2006 suggested that premature ovarian insufficiency has been associated with abnormal cardiovascular risk factors and increased cardiovascular mortality and thus low AMH levels may be associated with atherosclerosis. ${ }^{5}$ Studies have also established the role of cardiometabolic factors like hsCRP and lipids with AMH in humans. Similarly, the role of premenopausal AMH concentration has been inversely associated with subsequent atherosclerotic risk in macaques. ${ }^{6}$ 
Research over the last decade have focused on elevated levels of amino acid homocysteine (Hcy) as an independent risk factor for vascular disease Homocysteine, a sulfhydryl-containing amino acid, is an intermediate product in the normal biosynthesis of the amino acids' methionine and cysteine. It is biosynthesized from methionine via a multi-step process by the removal of its terminal $\mathrm{C} \varepsilon$ methyl group. Genetically determined enzymes and environmental factors determine the concentration of plasma Hcy. There has been an indication towards a significant correlation between hyperhomocysteinemia and cardiovascular disease (CVD) and its complications such as heart attacks and strokes. ${ }^{7}$ The possible link may be a homocysteineinduced reduction in the concentration of high-density lipoproteins (HDLs). ${ }^{8,9}$

Hcy mediated enhanced lipid peroxidation and generation of free radicals result in endothelial dysfunction also seems to be a factor for the increased level of Hcy in atherosclerosis. The levels of Hcy, which act an independent risk factor for atherosclerosis, are diminished by estrogen. With atherosclerosis remaining as the leading cause of morbidity and mortality, earlier detection of atherosclerosis will help in providing novel management strategies.

Hence present hypotheses were to determine the association of AMH and Hcy (which is a cardiometabolic risk factor) in premenopaual females with and without established disease as compared to normal and menopausal females for earlier identification of women at risk for atherosclerosis.

\section{METHODS}

The present study was designed as an age matched case control study, approved by the ethical committee conducted in a tertiary care teaching hospital and research center in central India. Since the project was a short-term studentship 2 months project approved by ICMR universal sampling method was taken into consideration. After taking informed consent, thirty premenopausal fertile females (group IIa, $\mathrm{n}=30$ ).

Family history of onset of menopause and with signs and symptoms of irregular menstrual cycles, hot flashes, sleep problems, vaginal dryness) were compared with thirty fertile normal females (group Ia, $n=30$ ) with regular menstrual cycles. Group IIIa $(n=30)$ included menopausal females (females with symptoms and no menstrual cycle for the last one year). Another group consisted of females of Group Ib, IIb and IIIb associated with known cardiovascular disease (CVD) as diagnosed by a physician. These were labeled as group Ib (normal females with CVD), IIb (premenopausal females with CVD) and III b (Menopausal females with CVD). All the participants were willing to participate and were without any history or signs and symptoms of any major illness.

\section{Exclusion criteria}

- Patients with any chronic inflammatory disease, diabetes mellitus, renal disorders, hypothyroidism, nephritic syndrome, obstructive liver disease, high BMI $\left(30 \mathrm{~kg} / \mathrm{m}^{2}\right)$, and heart disease (in Ia, IIa, IIIa), personal or family $\mathrm{H} / \mathrm{O}$ of hyperlipidemia, females with systemic drug therapy of $\beta$ blockers such as: thiazides retinoids, cyclosporine and lipid lowering agents in the recent month were excluded from the study with the help of a physician .

Excepting CVD all the exclusion criteria were taken into consideration for the Ib, IIb and IIIb group. Any patient not willing to co-operate after initially signing the informed consent was allowed to withdraw from the study. Fasting venous blood samples $(5 \mathrm{ml})$ were obtained to estimate Hcy and AMH status. Blood specimens were collected in vacutainer tubes as required. Serum was separated and then stored frozen $\left(-80^{\circ} \mathrm{C}\right)$ until analysis. The serum was analyzed for homocysteine (Enzyme linked immunosorbent assay) and AMH (Enzyme Linked fluorescent assay) by kit method.

\section{Statistical analysis}

Statistical analysis of difference was estimated using Epi Info version 7.1.1.14 statistical software (Centers for disease Control and Prevention, Atlanta, GA, USA) for mean, standard deviation, ' $t$ ' test and chi square test. Chisquare test was used to find out statistical significance of differences in proportions. A " $p$ " value of $<0.05$ was considered to be statistically significant. Correlation between variables was studied using Pearson's correlation coefficient test.

\section{RESULTS}

As in Table 1, the levels of AMH are significantly decreased in menopause and premenopause females without CVD as compared to normal fertile females. However, there is no significant difference in the levels of Hcy in between the groups.

As depicted in Table 2, the levels of both AMH and Hcy are non-significantly altered when the premenopause and menopause females with CVD are compared with fertile females with CVD. The data also suggests that though Hcy is increased in patients with CVD compared to normal groups, though its association with $\mathrm{AMH}$ is not significant. The inter group comparison between females with and without CVD reveals that $\mathrm{AMH}$ is significantly altered $(\mathrm{p}<0.001)$ in all the groups whereas Hcy is significantly increased $(\mathrm{p}<0.001)$ in normal fertile and premenopausal females (Table 3). Moreover, there was a weak correlation in between the parameters when intergroup comparison was made between AMH and Hcy in premenopausal $(-0.21,0.02)$ and menopausal $(0.07,0.13)$ females with and without CVD. 
Table 1: AMH and homocysteine levels in normal fertile, premenopausal and menopausal females.

\begin{tabular}{|c|c|c|c|c|c|}
\hline Parameters & $\begin{array}{l}\text { Normal fertile } \\
\text { females }(\mathbf{n}=\mathbf{3 0}) \text { (Ia) }\end{array}$ & $\begin{array}{l}\text { Pre-menopause } \\
\text { females }(n=30) \text { (IIa) }\end{array}$ & $\begin{array}{l}\text { Menopausal females } \\
(\mathbf{n = 3 0} \text { (IIIa) }\end{array}$ & $P$ value & $\begin{array}{l}\text { Chi } \\
\text { square }\end{array}$ \\
\hline AMH (ng/ml) & $7.24 \pm 1.75$ & $1.38 \pm 0.96^{*}$ & $0.62 \pm 2.53 * \#$ & 0.7002 & 0.7128 \\
\hline Homocysteine $(\mu \mathrm{mol} / \mathrm{L})$ & $21.33 \pm 6.75$ & $37.27 \pm 6.06^{*}$ & $38.70 \pm 13.07 *$ & 0.0000002 & 44.512 \\
\hline
\end{tabular}

Table 2: AMH and homocysteine levels in normal fertile, premenopausal and menopausal females with CVD.

\begin{tabular}{|l|l|l|l|l|l|}
\hline Parameters & $\begin{array}{l}\text { Group Ib } \\
(\mathbf{n = 3 0})\end{array}$ & $\begin{array}{l}\text { Group Ilb } \\
(\mathbf{n = 3 0})\end{array}$ & $\begin{array}{l}\text { Group IIIlb } \\
(\mathbf{n = 3 0})\end{array}$ & $\begin{array}{l}\text { P value } \\
\text { Square }\end{array}$ \\
\hline AMH $(\mathrm{ng} / \mathrm{ml})$ & $6.27 \pm 2.53298$ & $1.66667 \pm 0.88992$ & $0.759 \pm 0.52$ & 0.00000000037 & 69.52 \\
\hline Homocysteine $(\mu \mathrm{mol} / \mathrm{L})$ & $44.6667 \pm 15.0936$ & $47.4667 \pm 14.1293$ & $51.1333 \pm 13.3591$ & 0.00000000007 & 83.781 \\
\hline
\end{tabular}

Table 3: P value of biochemical parameters within groups with and without CVD.

\begin{tabular}{|l|l|l|l|}
\hline & Controls $(\mathrm{n}=\mathbf{3 0})$ & Perimenopause $(\mathrm{n}=30)$ & Menopause $(\mathrm{n}=\mathbf{3 0})$ \\
\hline AMH $(\mathrm{ng} / \mathrm{ml})$ & 0.05 & 0.67 & 0.42 \\
\hline Homocysteine $(\mu \mathrm{mol} / \mathrm{L})$ & $<0.0001$ & 0.001 & 0.00003 \\
\hline
\end{tabular}

\section{DISCUSSION}

It is long known that females in the menopausal age are more susceptible to cardiovascular episodes. Proposed mechanisms of this association include the sudden decrease of estrogen exposure along with other factors, contributing to the increased CVD risk with putative effects on vasculature and cardiac function. ${ }^{10,11}$ The underlying atherosclerosis likely develops over a period of decades and hence there is a need improved method of assessment that would allow earlier identification of women at risk for CVD. This gap in knowledge regarding the initiation and progression of atherosclerosis is in the transition phase. Present study was restricted to assess the status AMH and Hcy in different stages of females as they progressed from fertile to menopause and were compared with those suffering from CVD. AMH is a gonadal hormone that is dimorphic, and it is said to regulate vascular development and maintenance. As such though the presence of $\mathrm{AMH}$ in adult blood has been known, no function has been attributed. Present study demonstrates the fact that AMH levels were significantly decreased in premenopausal and menopausal females when compared with control group. This is in correlation with Freeman et al, and Shaw CM et al. ${ }^{12,13}$ A marker associated with cardiovascular disease is Hcy where in Hcy mediated enhanced lipid peroxidation and generation of free radicals result in inflammation could be related to the acute endothelial dysfunction. The antiatherothrombotic function of endothelium derived nitric oxide is also reduced due to the autooxidation of Hcy. Increased Hcy also stimulates the LDL oxidase property which potentially promotes atherogenesis. ${ }^{14}$ Moderate hyperhomocysteinemia has been identified as a new independent risk factor for CVD. In present study Hcy levels are increased in premenopausal and menopausal females when compared with control group. This is in correlation with studies of Gambacciani M et al and Hak AE. ${ }^{15,16}$ Woutersin in his study found increased levels of Hcy in menopausal women as compared to premenopausal women. ${ }^{17}$ Little is known regarding the relationship between Hcy and AMH in premenopausal and menopausal females, though a lot has been studied regarding other CVD risk parameters. Susan et al in their study for the first time reported an inverse relationship between $\mathrm{AMH}$ and subsequent atherosclerosis risk in female cynomolgus macaques. ${ }^{6}$ AMH is said to be a novel putative regulator of the cardiovascular system like other members of the TGF superfamily. as its downstream signaling is common with the bone morphogenetic proteins, which regulate vascular development and maintenance. ${ }^{11}$ Though Annelein et al, postulated that the decline of circulating AMH levels may be part of the pathophysiology of the increased cardiovascular risk of earlier menopause present study does not demonstrate any significant relationship between $\mathrm{AMH}$ and $\mathrm{Hcy}$ in premenopausal and menopausal patients. ${ }^{18}$ The major limitation of this study was the small sample size, assessment of vitamin levels and nonconsideration of differences among women in menopausal transition experiences. Conducting a prospective study (i.e., cohort study) than a case control study might help researchers to better understand the association between AMH and the risk of CVD. Thus, future prospective investigations along with multiple parameters with a larger sample size need to explore for the association of $\mathrm{AMH}$ as a risk factor for atherosclerosis in premenopausal females.

\section{ACKNOWLEDGMENTS}

Authors would like to thank Department of Gynecology and Obstetrics for their support in identifying the subjects. 
Funding: No funding sources

Conflict of interest: None declared

Ethical approval: The study was approved by the Institutional Ethics Committee

\section{REFERENCES}

1. Kim ES, Menon V. Status of women in cardiovascular clinical trials. Arterioscler Thromb Vasc Biol. 2009;29:279-83.

2. Yang XP, Reckelhoff JF. Estrogen, hormonal replacement therapy and cardiovascular disease. Curr Opin Nephrol Hypertens. 2011;20(2): 133-8.

3. E Vet A, Laven JS, de Jong FH, Themmen AP, Fauser BC. Antimullerian hormone serum levels: a putative marker for overian aging. Fertil Steril. 2002; 77:357-2.

4. Sirsikar M, Pinnelli V, Mohanty S, Jayashankar CA. Anti-Müllerian hormone in health and disease: a review. Int J Res Med Sci. 2016; 4(7):2514-20.

5. Atsma F, Bartelink ML, Grobbee DE, van der Schouw YT. Postmenopausal status and early menopause as independent risk factors for cardiovascular disease: a meta-analysis. Menopause. 2006;13(2):265-79.

6. Susan E, Haiying Chen, Thomas B Clarkson. Jay R Kaplan. Premenopausal antimüllerian hormone concentration is associated with subsequent atherosclerosis. Menopause. 2012;19(12): 1353-9.

7. Ganguly P, Alam SF. Role of homocysteine in the development of cardiovascular disease. Nutrit J. 2015;14(1):6.

8. Liao D, Tan H, Hui R, Li Z, Jiang X, Gaubatz J, et al. Hyperhomocysteinemia decreases circulating HDL by inhibiting apoA-I protein synthesis and enhancing HDL-C clearance. Circ Res. 2006;99:598606.

9. Zhao Z, Wang H, Jessup JA, Lindsey SH, Chappell MC, Groban L. Role of estrogen in diastolic dysfunction. Am J Physiol Heart Circ Physiol. 2014;306: H628-40.

10. Crandall CJ, Barrett-Connor E. Endogenous sex steroid levels and cardiovascular disease in relation to the menopause: a systematic review. Endocrinol Metab Clin North Am. 2013;42:227-3.

11. Lowery JW, de Caestecker MP. BMP signaling in vascular development and disease. Cytokine Growth Factor Reviews. 2010;21(4):287-98.

12. Freeman EW, Sammel MD, Lin H, Gracia CR. AntiMullerian hormone as a predictor of time to menopause in late reproductive age women. J Clin Endocrinol Metab. 2012;97(5):1673-80.

13. Shaw CM, Stanczyk FZ, Egleston BL, Kahle LL, Spittle CS, Godwin AK, et al. Serum antimüllerian hormone in healthy premenopausal women. Fertil Steril. 2011;95(8):2718-21.

14. Zhang C, Yong C, Adachi MT, Oshiro S, Aso T, Kaufman RJ. Homocysteine induces programmed cell death in human vascular endothelial cells through the activation of the unfolded protein response. J Biol Chem. 2001;276:35867-4.

15. Gambacciani M, Mannella P. Homocysteine, menopause and cardiovascular disease. Menopause Int. 2007;13(1):23-6.

16. Hak AE, Polderman KH, Westendorp IC, Jakobs C, Hofman A, Witteman JC, et al. Increased plasma homocysteine after menopause. Atheroscler. 2000;149(1):163-8.

17. Wouters MG, Moorrees MT, van der Mooren MJ, Blom HJ, Boers GH, et al. Plasma homocysteine and menopausal status. Eur J Clin Invest. 1995;25(11):801-5.

18. De Kat AC, Verschuren WM, Eijkemans MJ, Broekmans FJ, Van Der Schouw YT. Anti-Müllerian hormone trajectories are associated with cardiovascular disease in women clinical perspective: results from the Doetinchem cohort study. Circulat. 2017;135(6):556-65.

Cite this article as: Khan $\mathrm{H}$, Gupta MM. Serum anti-Mullerian hormone and homocysteine in premenopausal females with and without cardiovascular disease. Int J Reprod Contracept Obstet Gynecol 2019;8:479-82. 